\title{
MASTER
}

\section{THE TIME-STEPPED ENERGY SYSTEM OPTIMIZATION MODEL (TESOM): OVERVIEW AND SPECIAL FEATURES}

\author{
A.S. KYDES AND J. RABINOWITZ
}

December 1979

DEPARTMENT OF ENERGY AND ENVIRONMENT

BROOKHAVEN NATIONAL LABORATORY UPTON, NEW YORK 11973 


\section{DISCLAIMER}

This report was prepared as an account of work sponsored by an agency of the United States Government. Neither the United States Government nor any agency Thereof, nor any of their employees, makes any warranty, express or implied, or assumes any legal liability or responsibility for the accuracy, completeness, or usefulness of any information, apparatus, product, or process disclosed, or represents that its use would not infringe privately owned rights. Reference herein to any specific commercial product, process, or service by trade name, trademark, manufacturer, or otherwise does not necessarily constitute or imply its endorsement, recommendation, or favoring by the United States Government or any agency thereof. The views and opinions of authors expressed herein do not necessarily state or reflect those of the United States Government or any agency thereof. 


\section{DISCLAIMER}

Portions of this document may be illegible in electronic image products. Images are produced from the best available original document. 
BNL 51095

UC-13

\section{MASTER}

[General, Miscellaneous, and Progress

Reports (Nonnuclear)- TID-4500]

\section{THE TIME-STEPPED ENERGY SYSTEM \\ OPTIMIZATION MODEL (TESOM): \\ OVERVIEW AND SPECIAL FEATURES}

\section{A.S. KYDES AND J. RABINOWITZ}

December 1979

Andy S. Kydes, Head

ENERGY DATA AND MODELS

NATIONAL CENTER FOR ANALYSIS OF ENERGY SYSTEMS

DEPARTMENT OF ENERGY AND ENVIRONMENT

BROOKHAVEN NATIONAL LABORATORY

ASSOCIATED UNIVERSITIES, INC.

UNDER CONTRACT NO. DE-AC02-76CHO0016 WITH THE

UNITED STATES DEPARTMENT OF ENERGY 
$\because$

\section{DISCLAIMER}

I'his book was prepared as an account of work sponsored hy an agency of the United States Guvernment. Neither the United States Government nor any agency thereof, nor any of their employees, makes any warranty, express or implied, or assumes any legal liability or responsibility for the accuracy, completeness, or usefulness of any intormation, apparatus, pruduci, u1 pun iss diselood, or ropresents that its use would not infringe privately owned rights. Reference herein to any specific commercial product, process, or service by trade name, trademark, manulacluicr, or othcriwles, dus: not necessarily constitute or imply its endorsement, recommendation, or favoring by the United States Government or any agency thereof. The views and opinions of authors expressed herein do not necessarily state or reflect those of the United States Government or any agency thereof.

Printed in the United States of America

Available from

National Technical Information Service

U.S. Department of Commerce

5285 Port Royal Road

Springfield, VA 22161

Price: Printed Copy $\$$; Microfiche

$\mathrm{AO}_{2}$

too 


\section{Abstract}

This paper provides an overview of TESOM, a time-dependent energy Intergrating model used at Brookhaven National Laboratory for energy systems analysis. Special control theoretic features which act to smooth the intertemporal transitions between time periods are highlighted. These features include a new market penetration algorithm, an explicit representation of the technological and cost behavior of inherited (vintaged) stock, and the incorporation of risk factors in resource pricing.

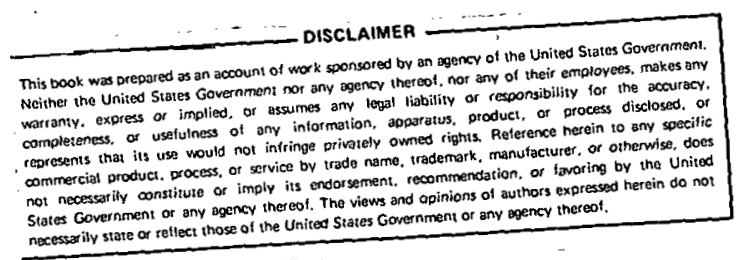


CONTENTS

1. Introduction .. ................... 1

2. Overview of TESOM ................. 1

3. Special Features ................ . 6

3.1. Electric Sector Formulation ... . . . . . 6

3.2. Time Dependent Adjustments ............ 9

3.2:1. Inventory Characterizations Over Time ... 9

3.2.2. Market Pentulration Adjustments ...... 10

3.2.3. Supply-Demand kepresentationc . . . . . 12

References ................... 14

F1gure 1. Reference Energy System ............. 16 


\section{INTRODUCTION}

The intent of this paper is to provide a clear descriptive overview of the Time-stepped Energy System Optimization Mode1 (TESOM), the Brookhaven National Laboratory energy system integrating model.

The scope of energy systems analysis includes not only energy-economy interactions and their implications for policy planning but also social concerns and security requirements and their interactions with energy use and the economy. The quality of an energy system cannot be judged solely by economic considerations. Social concerns and security currently compete with the goal of system cost minimization. ${ }^{1}$ It is essential to identify and employ approaches and a systems framework which facilitate the evaluation and characterization of an energy system by multiple criteria. ${ }^{2}$ An optimization framework is particularly well suited to the task of performing trade-off analysis when the criteria are quantifiable. ${ }^{3}$ One such established framework is the BNL/DJA* approach, which couples macroeconomic driving variables to energy-economy process models to derive internally consistent energy-economy projections. ${ }^{4}$ TESOM is the energy system component of this energy-economy modeling framework.

The combination of time- and device-dependent features permits a comprehensive analytic framework for performing technology assessments and policy analysis related to the role of government in affecting the direction of $R \& D$. The proper role of government in this area is to reduce or eliminate the barriers to R\&D for those technologies which may be attractive in the long run but which present too high a risk or initial investment for commercial establiohments tu Intitiate the process of development. Those technologies which are clearly cost-effective, or ineffective, will not require government intervention. It is this type of analysis for which TESOM is particularly we11 suited.

\section{OVERVIEW OF TESOM}

The Brookhaven Time-stepped Energy System Optimfzation Mode1, TESSOM, io a single reglon, time-stepped (sequential) linear programming model that was developed for the quantitative evaluation of national energy technologies and policies within a dynamic system's framework. The model is designed

*BNL/DJA: Brookhaven National Laboratory/Dale W. Jorgensen Associates. 
to examine interfuel substitution in the context of time-dependent constraints on the availability of competing resources and technologies (stocks) and their associated costs.

TESOM is structured around the Reference Energy System (RES) that depicts the flow of energy from a resource to the point of actual end use. The RES is a specialized format for representing the detailed technological structure of the energy system along with resource consumption and associated emissions. Conceptually, the RES is a network representation of the flow of energy from resourcc extractinn, through all intermediate converion processes, to the satisLation of flnit energy service needs (e.g., space heating, air condiclonilig, etc.). The RES provides a complete and thermodynamleally consictent energy accuunling system, in physical units, for energy flow through energy conversion devices: the extraction or importation of primary energy resulices and produrrs; refining and the various stages of energy conversion, transportation, distribution, and storage; and consumption of fuels and electricity by end-use technologies corresponding to particular energy service demands. Witnin the RES, emphasis is placed on the comprehensive technological structure relating the energy flows which enter the system (e.g., oil) to the nonsubstitutable, functional energy services which are the final products of the flow (e.g., process heat). A sample RES is shown in Figure 1.

The time-stepped model optimally allocates energy resources and products and selert.s the optimal mix of supply, cunversion, and demand technologies according lu selectud energy, envirnnmental, or economic criter1a (usually lcact cost) to satisfy a set of energy service demands. Energy service demand représentations are specified as exogenous requirements by year or as annual growth rates. Resource supply represcntations are specifled as long- or short-term supply curves or fixed prices and avallabilities by year. The TESOM motel provides a "vintage" representation of the nuliun's encrgy system in that the oplimal levels of the decision variables for any time perlod are determined from lie tollowing:

- The optimal levels established for previous periods;

- The retïrement and deterioration rates, the lifetimes, and the associated costs of vintage capital stocks;

- Economic and technological factors affecting the Itasible lcvels of the decision variables for the period under investigation (e.g., decline rates, supply elasticities, cumulative resource availabilities, market penetration considerations). 
Mathematically, the model is formulated as a sequence of expanding linear programing formulations of the RES--one for each time period. For a given time period, the solutions derived for earlier periods along with assumptions regarding retirement rates, average lifetimes, age-dependent conversion efficiencies, plant factors, operation and maintenance costs, and the capital charges for the stocks-in-place are incorporated into the sequenced formulation. Energy demands are satisfied in accordance with the supply expansions and increased penetrations that are attainable for the period, the net resource and stock availabilities from the evolution of the energy system to date, and the objective function criteria selected. In meeting future energy demands, TESOM has a memory of the net availabilities from the past augmented by that which is attainable in the near-term. The updating and sequencing procedures are repeated until solutions for the entire time horizon are determined.

The input information required for the model falls into seven general time-dependent categories: (1) supply and demand efficiencles, (2) costs, (3) environmental impact factors, (4) resource avallabilities (entered explicitly or generated by submodels), (5) basic energy demands (entered explicitly or computed with growth rates), (6) permitted optimistic market penetration levels, and (7) demand load characteristics of all electric service demands.

The supply efficiencies, which relate intermedlate energy forms to primary resources, include efficiencies for refining, electric conversion, transmission and distribution of electricity and by-product heat, and synthetic fuel manufacturing. A refining efficiency represents a combined extraction, cleaning, and transportation efficiency and is defined as the ratio of the useful energy content of the fuel delivered to the user to the energy content at the minemouth or wellhead. In addition to these supply efficiencies, effective end-use utilization efficiencies must be specified for each utilizing device. Finally, efficiency and electric generation plant factor decay rates must be specified for all conversion equipment as a function of age.

The coots considered in TESUM include charges for investment in capital equipment, operation and maintenance of the stock, transmission and distribution of electricity, and resource consumption. Capital recovery costs are associated with each individual supply category and end-use 
device. Also specified are maximum utilization factors for electric generation plant types. The actual capacity factor is determined by the model and is related to the load factor of the demands served by each technology.

Environmental coefficients are associated with each process in the various fuel paths from primary resource supply to end use. The total emissions for each process are calculated and summed.

Six main categories of constraint equations are used in TESOM:

(1.) Energy conservation process equations balance the energy content of fugls into a process with the energy content of fuels out of a process including energy losses.

(2) Supply cquations 1.imit the amount of a given resource, at a given price, in terms of the energy content of the primary fuel (Iniliemouth and wellhead) available from that supply category. For synthetic fuels, the supply constraint equations represent the energy content of the synthetic fuel after manufacturing.

(3) Demand equations specify the level of nonsubstitutable functional end-use energy demands; each basic energy demand is defined as the amount of cncrgy required to support an energy utilizing activity (e,g., residential space heat) assuming that the energy could be used at $100 \%$ technical erficiency (after conversion). Basic energÿ denands are specified hy level or by growth rate for each of the demand categorles.

(4) Electrical supply and demand load characterization equations limit the electrical generating capacity of plant types as well as accounting for peak electric demands and energy balances. The load characterization equations relate the type and quantity of electric generating capacity to the demand load characteristics of each demand type by season and time of day.

(5) Environmencal cuistrainte limjt emissions of various types, such as sulfur dioxide or particulates. In moat model runs these constraints are nonbinding and serve only to sum up environmental residuals.

(6) Market penetration equations limit the technology penetration of markets and define the range of permiesible fuel usage or permitted capacity of a particular type of energy conversion process.

TESOM provides a time-dependent representation of the electric sector; Certain of the energy service demands may be satisfied by electricity. However, 
the simple summation of the electricity inputs to these end-use devices does not determine the generating capacity which must be installed. Rather, a set of demand types (e.g., base and intermediate loads, off-peak, heating, cooling, etc.) are defined. Each demand type has its own set of characteristics regarding its stochastic behavior and its seasonal (winter, summer, fallspring) and daily (day, night) loading. Required capacity is governed by the highest total peak demand which occurs during any time of the year and day. By appropriately loading the electric energy service demands onto the various (or, in some cases, corresponding) demand types and, subsequently, loading these onto the various season-day combinations, the height of the total peak for each season-day is determined. Required capacity is simply the maximum of the individual season-time-of-day peaks with allowances for transmission and distribution losses and reserve margins. This feature permits the introduction of load management considerations into the problem formulation as the load duration curve is, in part, exogenously determined from the detailed demand characteristics and their implications for the electric system.

The model contains a number of features designed to smooth the intertemporal transitions indicated by the sequence of solutions. Among these are the mechanism for pricing and adjusting the availabilities of vintage stocks and an improved market penetration algorithm which avoids the all-or-nothing (bang-bang) characteristic of linear programming models. The annualized capital charges for a technology impose a cost on the system as long as the age of a vintage . stock is within its economic lifetime. Thus, fixed costs associated with previous investments are incurred regardless of whether or not it is optimal to operate, partially or fully, an older technology. "Unrealistic" dispiacements of relatively inefficient vintages are discouraged when the associated variable costs of alternative stocks are combined with the fact that immediate writeoffs are precluded.

The procedure for market penetration requires, as input, "optimistic" penetration levels for each technology in each year. The penetration algorithm then incorporates the marginal values, implementation rates, and lag times from previous periods as well as the technological and market characteristics for the current pertod into the determination of more realistic bounds for the activity levels. The user-specified bounds are adjusted endogenously to account for the previous penetration and attractiveness of the technology. 


\section{SPECIAL FEATURES}

\subsection{Electric Sector Formulation}

The formulation of the electric sector in TESOM. incorporates the essentials of capacity expansion, generation, and transmission of electricity and by-product heat and their relation to the stochastic behavior of electric demands. On the electric conversion side, central station electric power plants deliver their high voltage electricity to a network "pool" from which the demand sectors draw energy to satisfy their needs. Conservation of energy relations link the electrlc generation side, with associated capacity requirements, to the demand slde. Empirical evidence also shows that the demand for electricity is both seasullally and time-nf-day. dependent, and this has led to the natural partition of the year into six season and time-of-day divisions (winter day, winter night, summer day, sumer night, fall-spring day, fall-spring night). On the demand side, the determinants of the load-duration curves which ultimately define capacity needs are "demand types": (base load, Intermediats loar, etc.) and not demands (space heating). Each of these demand types has a primary load factor and a set of secondary load factors. The primary load factor characterizes the major component of the demand type whereas the secondary load factors describe the demand type's stochastic behavior.

Each type of demand for electricity (e.g., epace heating) is fractionally distributed amiong each of the relevant demand types. These demand types, coupled with the primary and secondary load factors, act to generate required capacity to meet the potential demand for electricity in each season-time-of-day period. Capacity is built to meet the maximum load period.

The key capacity equation which defines this process is described below. A complete list of equations is given by Kydes and Rabinowitr. 5 Let

\footnotetext{
$\mathrm{DE}=$ the set of end-use encrgy demand categorfes, e.g., residential space heating, process heating, etc.;

DT $=$ the set of demand types, e.g., base load, intermediate load, off-peak, etc.;

$E(D E)=$ the amount of electricity utilized by demand $D E$, and is a dec1sion variable for the optimization process;

$\operatorname{ECS}(D E)=$ the amount of centralized electricity utilized by demand DE;
} 
$D E C=$ the set of decentralized electricity generating plant types, e.g., total energy system, fuel cell, small wind system;

$E(D E C)(D E)=$ the amount of electricity generated by decentralized plant type DEC utilized by demand DE;

te $=$ the long distance, high voltage transmission efficiency;

rmcs $=$ the reserve margin required for the central station pool;

$\mathrm{rm}(\mathrm{DEC})=$ the reserve margin required for decentralized plant type $D E C$;

$\alpha(D E, D T)=$ the fraction of demand DE which is loaded onto demand type DT as specified by the user, e.g., $70 \%$ of process heat may be base loaded while $30 \%$ is intermediate load;

$S=$ the set of seasons: winter, summer, fall-spring;

$\mathrm{T}=$ the time of day: day, night;

$\mu(\mathrm{S}, \mathrm{T}, \mathrm{DT})=1$ if demand type DT occurs during season $\mathrm{S}$ and time-of-day $\mathrm{T}$; it equals zero otherwise;

$t 1(D T)=$ the fraction of the year demand type DT occurs, and, therefore, acts as the primary load factor;

$\mathrm{pf}(\mathrm{DT})=$ the peak fraction for demand type DT, which defines the fraction of the demand that occurs at the secondary load factors; specifically, $[1+p f(D T)]^{-1}$ occurs at the primary load factor and $\mathrm{pf}(\mathrm{DT}) /[1+\mathrm{pf}(\mathrm{DT})]$ occurs at the secondary load factors;

$f(i, D T)=$ the fraction of the secondary (peak) demand, associated with demand type DT, which is allocated to secondary peak interval $i$; $\operatorname{slf}(i, D T)=$ the load factor of the $i^{\text {th }}$ secondary (peak) interval associated with demand type DT.

The quantity $E(D E) * \alpha(D E, D T)$ represents the proration of demand $D E$ to demand type DT; this multiplied by $\mu(\mathrm{S}, \mathrm{T}, \mathrm{DT})$ distributes each demand type component to the appropriate season-time-of-day combinations. Hence,

$$
\mathrm{P}(\mathrm{DT}, \mathrm{S}, \mathrm{T})=\frac{\mathrm{E}(\mathrm{DE}) * \alpha(\mathrm{DE}, \mathrm{DT}) * \mu(\mathrm{S}, \mathrm{T}, \mathrm{DT})}{1+\mathrm{pf}(\mathrm{DT})}
$$

represents the quantity with a primary load faclur of demand type DT contributed by demand $D E$ during season $S$ time-of-day $T$. The quantity

$$
\mathrm{S}(\mathrm{DT}, \mathrm{S}, \mathrm{T})=\frac{\mathrm{E}(\mathrm{DE}) *_{\alpha}(\mathrm{DE}, \mathrm{DT}) * \mu(\mathrm{S}, \mathrm{T}, \mathrm{DT})}{1+\mathrm{pf}(\mathrm{DT})} * \mathrm{pf}(\mathrm{DT})
$$

represents the fraction of demand type DT contributed by demand DE occurring at the secondary (peaking) load factors. 
The translation of the electricity demands to installed generation capacity requires division of each component of demand type by the appropriate load factors. The parameter $t I(D T)$ is the primary load factor. The quantity $S(D T, S, T) * f(i, D T)$ represents the portion of the secondary contribution which has a secondary load factor of slf(i,DT). Capacity required to satisfy electricity demand $E(D E)$ during season $S$ time-of-day $T$, omitting transmission losses, is

$\frac{E(D E) * \alpha(D E, D T) * \mu(S, T, D T)}{[1+p f(D T)] * t(D T)}+\frac{E(D E) * \alpha(D E, D T) * \mu(S, T, D T)}{[1+p f(D T)]} * \operatorname{pf}(D T) * \sum \frac{f(i, D T)}{s 1 f(i, D T)}$

Tula1 capacity required prior to transmission losses lu saticfy a11 demands

for a pasticular season $S$ and time=ur-alay $T$ is

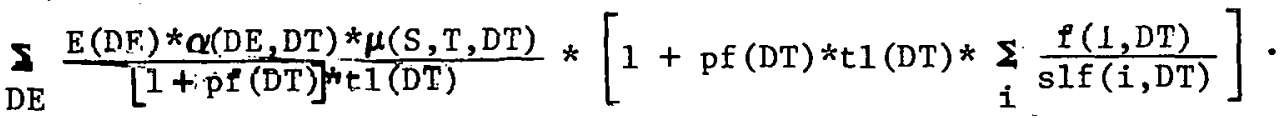

DT

A function which translates a unit of electricity demand into units of installed capacity can be defined as

$$
\mathrm{cm}(\mathrm{DE}, \mathrm{S}, \mathrm{T})=\sum_{\mathrm{DT}} \frac{\alpha(\mathrm{DE}, \mathrm{DT}) * \mu(\mathrm{S}, \mathrm{T}, \mathrm{DT})}{[1+\mathrm{pf}(\mathrm{DT})]^{* 1(\mathrm{DT})}} *[1+\mathrm{pf}(\mathrm{DT}) * \mathrm{t} 1(\mathrm{DT}) * \underset{i}{\mathbf{s} 1 \mathrm{f}(\mathrm{i}, \mathrm{DT})}] .
$$

Transmission and distribution losses can be incorporated by dividing the electricity utilization of each demand into electricity from the central station pool and electricity from each decentralized plart type. In addition, the incopporation of reserve margins yields a season $S$ time-of-day $T$ minimum. electricity generating capacity or

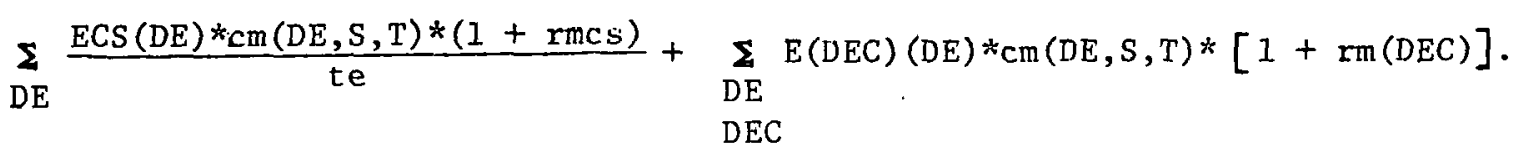

By capturing many of the essential components for building electric capacity, the electric formulation of TESOM represents a charactcristis property of simulation models, thal of rcflosting a causal relationship between the demand for electricity (and its stochactic propcrties) and the requirements for inscalled capacity and reserve margins. Further, since capacity is installed to meet the maximum load season-time-of-day combination, this formulation also explicitly captures the reality that substantial idle capacity will exist during portions of the year (mostly in the fall and spring seasons) while tlie systcm will operate at. nearly full capacity during other parts of the year. The current reality 
where differentiated pricing policies do not exist is also reflected. The effect of differentiated pricing policies can easily be captured using the facilities of demand loading and differential "mark-ups" for electricity use by sector developed for TESOM.

\subsection{Time-Dependent Adjustments}

3.2.1. Inventory Characterizations Over Time. For the intital time period, preferably an historical year, TESOM requires, as input, specifications for each kind of conversion device averaged over all stock in place. These "averaged" specifications include economic lifetime, capital cost., operation and maintenance cost, conversion efficiency, fixed charge rate, and years remaining in the economic lifetime. For following periods, generally future years, similar specifications are required, but they are expected to characterize new stock introduced in that period rather than an average of vintaged stock.

Investment costs are specified in constant dollars and are annualized by using a capital recovery factor which depends on the device's fixed charge rate and economic life. Specifically, if FCR is the fixed charge rate (interest rate) specified by device and year of introduction and LIFE is the economic life also specified by device and year of introduction, then the capital recovery factor is given by

$$
\frac{\text { FCR }}{1-(1+\text { FCR })^{-L I F E}} \text {. }
$$

Investment costs may also be specified as time dependent to reflect learning curves for advanced technologies; that is, initial investments may be high but may decline to some asymptotic val11e. The model eisures that annualized capital charges for equipment introduced in earlier periods continue to be paid over the economic lifetime of the device. This discourages premature retirement of equipment. Operation and maintenance charges are accrued by installed devices only if they are utilized (at a rate proportional to their usage).

Capital charges cease at the end of the economic life of the device even though some of the devices installed are available for use past their economic life. For a given device type let

$f=a$ fraction such that $f * L I F E$ is the number of years of potential operation beyond the economic lifetime; 


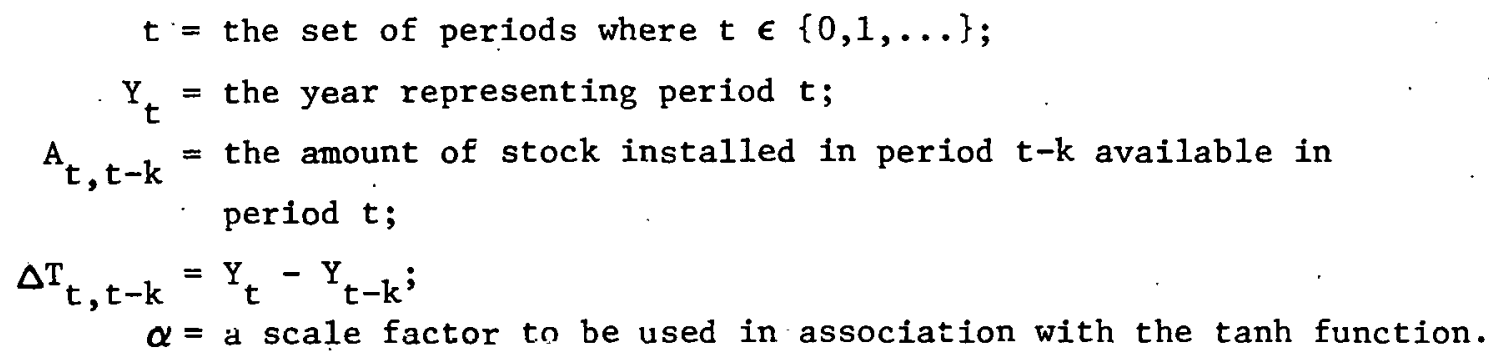

When $t-k \neq 0$,

$$
A_{t, t-k}= \begin{cases}A_{t-k, t-k} & \text { if } \Delta T_{t, t-k} \leq \text { LIFE } \\ 0 & \text { if } \Delta T_{t, t-k} \geq(1+f) * L I F E \\ A_{t-k, t-k}{ }^{* v_{t, t-k}} & \text { itherwice }\end{cases}
$$

where

$$
\gamma_{t, t-k} \equiv 1-\tanh \left[\frac{\alpha *\left(\Lambda^{\prime} L_{t, t-k}-\mathrm{LIFE}\right)}{\mathrm{f}^{*} \mathrm{LIFE}}\right] .
$$

Since the devices "introduced" in the initial period represent an "average" of vintage stock already in place, the availability of these devices over time is computed in a slightly different manner. ${ }^{5}$

To represent the aging of devices, the TESOM characterization of energy conversion technologies incorporates operation and waintenance cost growth rates, efficiency decay rates, and, tor eleclricity gcncrating plants, maximı availability factor decay rates. The maximum availability factor is defined to le the maximum traction of llie ycar that a given type of levice could be in operation. All of these growth/decay rates are assumed to be linear.

3.2.2. Market Penetration Adjustments. Market penetration, the gradual subetilution over time of a new commodity for one or uore existing commotities in satisfying basic consumption or production needs, is a process which must be captured in some form if the projection framework for evaluartng evulving energy systems is to have credtbility. Hurter and Rubenstein ${ }^{6}$ provide a general literature search and review of work lis thia arca. Condap and. Kydes ${ }^{7}$ discuss market penetration representations in relation to an important new class of energy equilibrium models, of which a typical example is the U.S. Department of Energy Long-range Energy Analysis Program (LEAP) 8 model. This class of models incorporates market penetration in an integrated framework.

The TESOM formulation permits a natural marriage of the traditional "stand-alone" market penetration algorithms ${ }^{9,10}$ with an integrated energy 
system's framework by incorporating cost effectiveness, time lags, and market shares, determined from the TESOM model, as the key coupling mechanisms to link with the traditional approaches.

For each type of energy conversion device (e.g., electricity generating plants, end-use devices) TESOM adjusts the optimistic market penetration rates through time. Marginal values are generated for each technology in the penetration algorithm by imposing small lower bounds for each year. To keep the problem size manageable, those device types which remain at the lower bound are deleted from the inventory rather than carried forward. If two conversion devices are equally attractive, "within noise" (as specified by the user), then the new capacities installed for each technology are proportional to the ratios of capacity expansion potential implied by the optimistic penetration rates. The time lags, marginal values, and current market shares are used to adjust the market penetration trajectory.

To define the market penetration optimistic upper bound adjustment algorithm for a given device, let

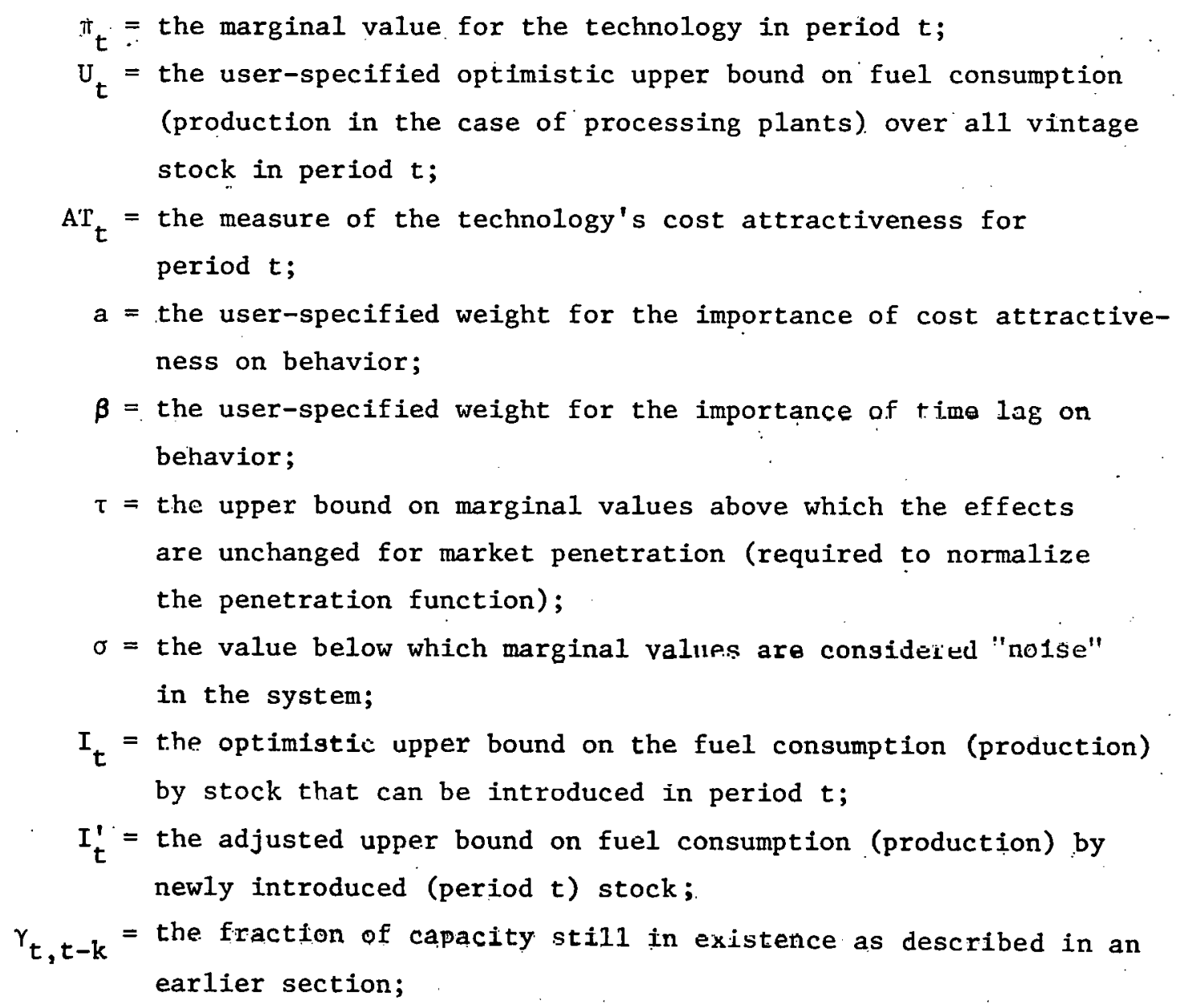




$$
\begin{aligned}
E_{t, t-k} & =\text { the conversion efficiency in period } t \text { of period } t-k \text { vintage stock; } \\
P & =\text { the most recent positive optimistic increment (see below). }
\end{aligned}
$$

The optimistic new stock upper bound is computed as

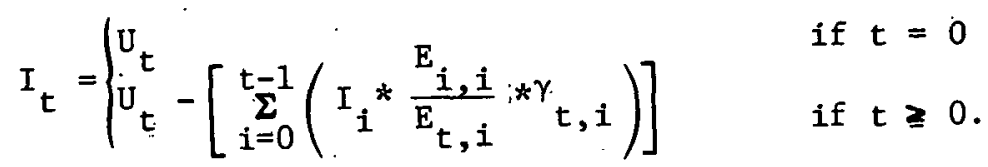

The parameter $P$, which is initialized to zero before period 0 , is set equal to $I_{t}$ if $I_{t} \geqq 0$.

The cost atractivenoss indicator is derived from the technology's marginal valuc in the prevluus pariod ss follows:

$$
\mathrm{AT}_{t}= \begin{cases}\tau & \text { if } \pi_{t-1} \geqq \tau \\ -\tau & \text { if } \pi_{t-1} \leqq-\tau \\ 0 & \text { if }\left|\pi_{t-1}\right| \leqq \sigma \\ \pi_{t-1} & \text { otherwise. }\end{cases}
$$

Finally the adjusted incremental upper bound is calculated as

$$
I_{t}^{\prime}=P * \tanh \left(a * A T_{t}+\beta * \Delta T_{t, t-1}\right) \text {. }
$$

The parameter $P$ rather than $I_{t}$ is used in the above calculation so that the overall penetration of the technology can continue to grow, up to the optimistic upper bound, even thnugh the optimistic increment may be less than or equal to zero.

By fixing the availability of old etock as described in an earlier sect1on and retricting the fuel consumption (production) by new stock to the adjusted increment upper bound, TESOM controls the market penatrotion of the technology for each vintage stock.

3.2.3 Supply-Demand Representations. Five supply representation options are currently available in TESOM. The user may sperify, for each resourcc,

- quantities of a given resource at different prices by resource type and year; or

- cumulative oupply curves or long-run marginal cust curves; or

- a short-run supply elasticity representation using, as Input, an Initial marginal price-quantity reference point with a supply elasticity for each resource and year; or

- a short-run supply elasticity representation overlayed on the cumulative supply curve; or

- short-run relative unit price increments between successive pools of resources with the initial "pool" reference price/quantity relationship determined from a cumulative supply curve. 
The first option represents individual short-run supply curves (price/ quantity relationships) for each year. The curves are represented by pools of resources available at specified prices (step functions).

The second option reflects the long-term effects of resource depletion and associated escalating costs due to declining discovery rates and is represented by using approximated long-run marginal cost curves which are year independent. Implicit is the assumption of that there is sufficient lead time for exploration and capital investment to reduce demand induced rents to zero. In other words, the marginal cost curve represents the replacement cost for the last unit of resource consumed.

The third option, the short-run elasticity representation, is derived from the definition of own-price elasticity; if $\widetilde{\mathrm{P}}$ is the reference marginal price for reference quantity $\tilde{Q}$ and $\sigma$ is the short-run own-price elasticity, then the own-price elasticity is defined by

$$
\frac{\partial Q / Q}{\partial P / P}=\sigma .
$$

Since $C(Q)$, the total cost to the system for using quantity $Q$, is found by noting that the marginal rate of resource cost is given by

$$
\frac{\mathrm{dC}(\mathrm{Q})}{\mathrm{dQ}}=\mathrm{P}(\mathrm{Q}) \text { with } \mathrm{C}(\tilde{\mathrm{Q}})=\tilde{\mathrm{P}} * \tilde{\mathrm{Q}} \text {, and } \sigma, \tilde{\mathrm{P}}, \tilde{\mathrm{Q}} \geqq 0 \text {, }
$$

then $C(Q)=\frac{\tilde{P} * \tilde{Q}}{1+\sigma}\left[\sigma(Q / \tilde{Q})^{1+1 / \sigma}+1\right]$.

If

$$
\begin{aligned}
q_{i}= & \text { the resource pool size available at a given price } p_{i} \text { where } p_{i} \text { is } \\
& \text { to be determined, and } \\
Q_{i}= & \text { cumulative quantity of the resource used, }
\end{aligned}
$$$$
\text { then } q_{i}=Q_{i}-Q_{i-1}, Q_{0}=0 \text {. }
$$

If the relation that the total cost to the system, evaluated at the endpoints of these pools of resources, equals the sum of the prices times the quantities used, i.e.,

$$
C\left(Q_{i}\right)=\sum_{k=1}^{i} p_{r} q_{r} \text { for all } i
$$

is enforced, then the price per unit resource for each pool is given hy

$$
P_{k}=\left[C\left(Q_{k}\right)-C\left(Q_{k-1}\right)\right] / q_{k}, k=1,2, \ldots .
$$

The $q_{k}$ are input; the $Q_{k}$ are computed as

$$
Q_{k}=Q_{k-1}+q_{k}, \quad k=1,2, \ldots
$$


The fourth alternative simply uses the marginal cost curve to derive the initial marginal price/quantity reference point for the short-run elasticity representation.

The fifth option requires that the user provide differences between the short-run quantity/price pools for a given resource. The cumulative supply curve provides the referencc marginal price from which the short-term curve is completely defined.

A measure of uncertainty in future resource prices is introduced in the decision process by adding an adjustment factor which reflects near-term resource "price expertations." If $P(t-1)$ and $P(t-2)$ are the marginal prices of a resnurce for periods $t-1$ and $t-2$ respet:tively, and if $\Delta(t-1, t-\%)$ is $t$ the time span between periods $t-1$ and $t-2$, then the adjusted price for period $t$ is given by

where

$$
P(t)+\frac{P(t-1)-P(t-2)}{\Delta(t-1, t-2)} * W
$$

$$
\frac{P(t-1)-P(t-2)}{\Delta(t-1, t-2)}
$$

represents the annual price growth rate in the previous two periods and $W$ is a "look ahead" weighting factor which implies price expectations by consumers.

\section{REFERENCES}

1. Hohhs, B. F. and Voelker, A. H., Analytical Multiobjective Declslunmaking Techniques and Power Plant S1ting: A Survey and Critique, ORNL 5288, Feb. 1978 .

2. Zionts, S. and Wallenius, J., An interactive prugraming method for solving the multicriteria problem, Mandagement icience 22 (6), 652-6J (1976).

3. Kydes, A. S., The Brookhaven Euelgy Systcm Optimizatinn Mndel, Its Variants and Uses, BNL 50873, May 1978.

4. Behling, D. J., Dutlien, R, and Hudson, E., The Relationship of Energy Growth to Economic Growth Under Alternative Energy Policies, BNL 50500, 1976.

5. Kydes, A. S. and Rabinowitz, J., The Time-Stepped Energy System Optimization Model, Methodology and Calibration, draft repurl, March 1980. 
6. Hurter, A. P., Jr. and Rubenstein, A. H., Market penetration by new innovations: The technological literature, Technological Forecasting and Social Change, Vol. II, 197-221, Elsevier North-Holland, Amsterdam, 1978.

7. Condap, R. and Kydes, A. S., Modeling Market Penetration with Emphasis on the DFI Energy-Economy System, BNL 50999, April 1979.

8. Adler, R. J., Cazalet, E. G., Haas, S. M., Marshalla, R. A., Nesbitt, D. M. and Phillips, R. L., The DFI Energy-Economy Modeling System, draft report, Decision Focus Inc., Palo Alto, CA, 1978.

9. Fisher, J. C. and Pry, R. H., A simple substitution model of technological change, Technological Forecasting and Social Change, Vol. III, 75-88 (1971).

10. Peterka, V. and Fleck. F., The Dynamics of Energy Systems and the Logistic Substitution Model, Vol. II, Theoretical Part, International Institute for Applied Systems Analysis (IIASA), AR-78-1B, July 1978. 


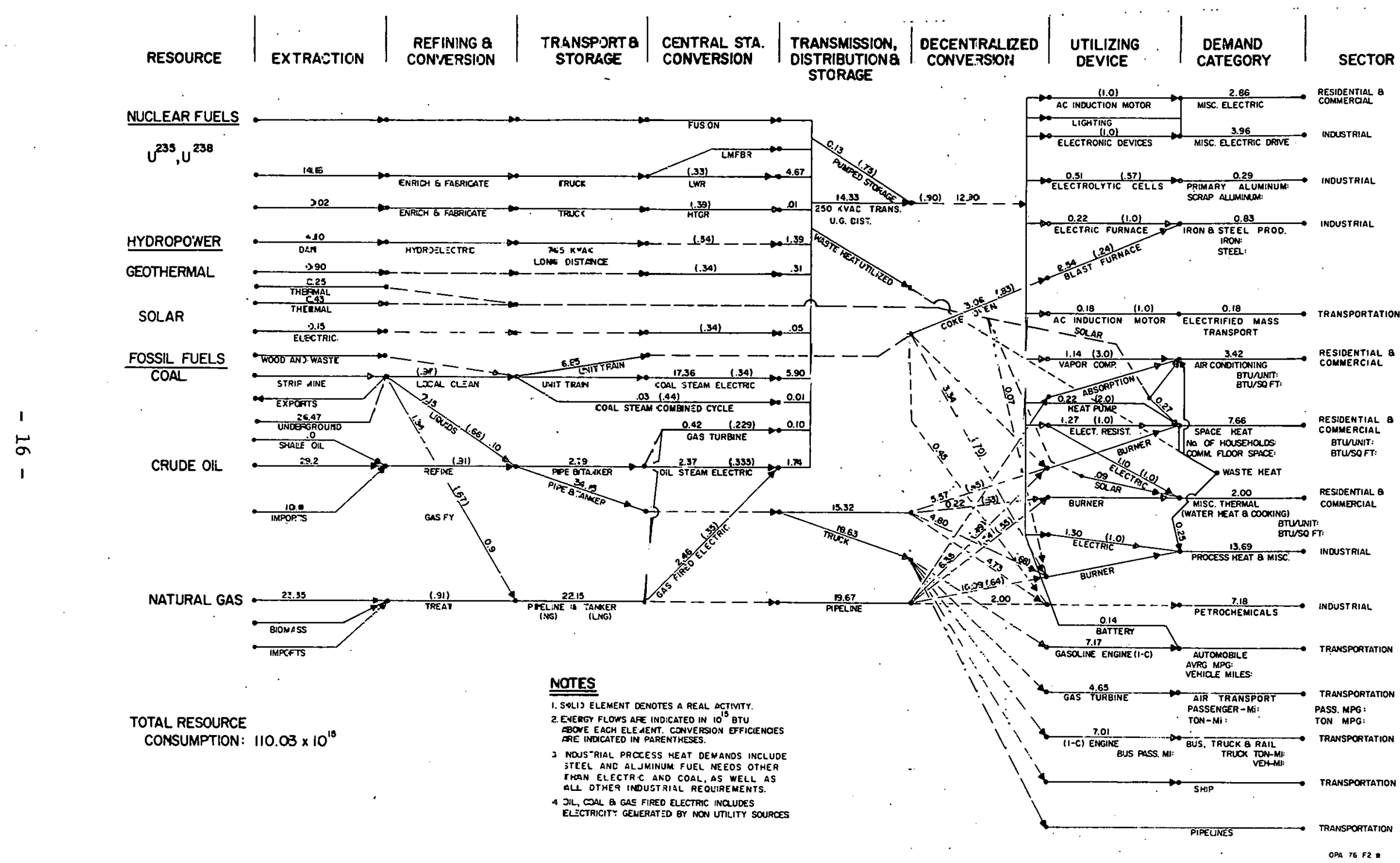

Fizure 1. Reīerence Energy System, Year 1990.. - 